
\title{
R Reserach S Suare \\ Curcumin Protects HepG2 Cells from the Cytotoxic Effect of Drugs with Anti-fibrotic Activity
}

\section{Mariana Y. Medina-Pizaño}

Autonomous University of Aguascalientes

Marina N. Medina-Rosales

Autonomous University of Aguascalientes

\section{Esperanza Sánchez-Alemán}

Autonomous University of Aguascalientes

\section{Sandra L. Martínez-Hernández}

Autonomous University of Aguascalientes

\section{Liseth R. Aldaba-Muruato}

Autonomous University of San Luis Potosí

Javier Ventura-Juarez

Autonomous University of Aguascalientes

Martin Humberto Muñoz-Ortega ( $\sim$ humberto.munozo@edu.uaa.mx )

Autonomous University of Aguascalientes

\section{Research Article}

Keywords: Cytotoxicity, $\alpha / \beta$ adrenoblockers, Curcumin, HepG2, Oxidative stress, Apoptosis

Posted Date: March 15th, 2021

DOl: https://doi.org/10.21203/rs.3.rs-289436/v1

License: (c) (i) This work is licensed under a Creative Commons Attribution 4.0 International License.

Read Full License 


\section{Abstract}

Background: The $\alpha$ and $\beta$ adrenoblockers have been tested as an alternative treatment for chronic liver lesions such as fibrosis and cirrhosis in animal models, as well as their possible participation during the regeneration of the damage caused by liver cirrhosis in a hamster model. However, it was observed that doxazosin caused slight morphological changes in hepatocytes, while that curcumin showed protection to the hepatic parenchyma. Regardless, the pharmacokinetic effects of these $\alpha / \beta$ adrenoblockers on the hepatocytes' cell viability, possibly involved in the hepatic parenchyma's repopulation during cirrhosis reversal, are unknown. The present study aimed to elucidate the protective effect of curcumin on the possible side effects of doxazosin, tamsulosin, and carvedilol on the HepG2 cell line, drugs already tested with antifibrotic activity.

Methods: HepG2 cells were exposed to $0.1,0.5,10$, and $25 \mu \mathrm{M}$ of doxazosin, carvedilol, and tamsulosin for 24,48 , and $72 \mathrm{~h}$, for curcumin, cells were pretreated with $1 \mu \mathrm{M}$ for $1 \mathrm{~h}$ before exposure to $\alpha$ and $\beta$ adrenoblockers. The cell viability was assessed by MTT assay. The morphological changes were determined using hematoxylin and eosin (H\&E) staining, scanning electron microscope (SEM), and acridine orange $(\mathrm{AO})$ staining.

Results: We observed that the doxazosin decreases cell viability dependently time and dose; carvedilol and tamsulosin increase cell proliferation. However, curcumin induces regulation of these effects in HepG2 cell line, increasing or maintaining viability compared to control. The pretreatment with curcumin regulated AST levels (aspartate aminotransferase) and ALT (alanine aminotransferase) in cells exposed to $\alpha$ and $\beta$ adrenoblockers. The SEM and H\&E staining provided evidence that doxazosin, carvedilol, and tamsulosin induced morphological changes in HepG2 cell line, depending on time and dose, approximately $80 \%$ of the cells treated with drugs were balonized, and curcumin protected these effects, maintaining the morphology in $90 \%$ of the treated cells.

Conclusions: The present study demonstrates that curcumin protected the HepG2 cells against cytotoxicity and morphological changes induced by the $\alpha$ and $\beta$ adrenoblockers attenuating secondary effects for possible oxidative stress. In this way, it is concluded that these treatments with antifibrotic effect, in co-treatment with curcumin, will not affect the possible repopulation process of the liver parenchyma during the reversion of fibrosis.

\section{Background}

In a hamster liver cirrhosis model, it was shown that treatment with doxazosin and carvedilol reduces the concentration of collagen fibers in the liver and improves liver parenchymal function with decreased AST and ALT. However, the a-1 antagonist (doxazosin) modified hepatocytes' typical morphology and affected the parenchyma's regeneration process [1]. Although the $\beta$ adrenoceptor blocker (carvedilol) is considered antifibrotic for its antioxidant activity in a liver cirrhosis model of rats treated with carbon tetrachloride and an in vitro model of a liver stellar cell line (LX-2), it can restore liver parenchyma due to liver stellar 
cells' inactivation and collagen; inhibition of collagen synthesis can also be done through the TGF $\beta 1 /$ SMAD pathway $[2,3]$.

Curcumin is bis- $a, \beta$-unsaturated $\beta$-diketone, with antioxidant activity [4]. The group ortho-methoxy of curcumin plays an essential role in oxidative stress. It reacts with reactive oxygen species, and hydrogen donation reactions lead to its oxidation and contribute to the well-established ROS-scavenging potential in the biological system [5].

Curcumin can positively regulate cytoprotective and antioxidant proteins. However, it has been shown that it can produce a pro-oxidant effect in high doses [6]. One of the primary defense mechanisms against cytotoxicity is the stimulation of Nrf2 activity and the activation of the antioxidant response element (ARE) Nrf2 signaling pathway, regulating the expression of genes involved in eliminating ROS [7].

In a study, the antifibrotic activity of doxazosin and carvedilol in co-treatment with curcumin in an in vivo model of hamsters with $\mathrm{CCl}_{4}$ was reversed fibrosis to decrease collagen I, hepatocyte morphology without alterations and, normal liver function. The antioxidant curcumin is proposed to increase mRNA expression of the Nrf2. On the other hand, the liver fibrosis process decreased the antioxidant response of factor 2 related to erythroid nuclear factor 2 (Nrf2) and increased the pro-inflammatory pathway of nuclear factor kappa B (NF-kB) [8].

Doxazosin and prazosin induced the apoptosis of cultured cardiomyocytes dose-dependently over the range 0.1 to $50 \mu \mathrm{mol} / \mathrm{L}$; this potential has been demonstrated for the two quinazoline-based antagonists, but they have not been observed with tamsulosin, which has a phenylethanolamine structure [9]. A concentration of $1 \mu \mathrm{mol} / \mathrm{L}$ in vitro is considered to ensure intracellular concentrations like those achieved in vivo by therapeutic doses (in patients, serum doxazosin concentration reaches $0.122 \mu \mathrm{mol} / \mathrm{L}$ with an 8 $\mathrm{mg}$ dose and $0.244 \mu \mathrm{mol} / \mathrm{L}$ with a $16 \mathrm{mg}$ dose) [10].

There is no critical understanding of effective liver repopulation requirements and mechanisms for treatment or reversal of liver fibrosis or cirrhosis. Different models of cirrhosis and fibrosis have been established in rodents to study a mechanism of progression of these diseases and/or antifibrotic therapies. The induced liver fibrosis by thioacetamide demonstrated that epithelial progenitor stem cells that are derived from the rat fetal liver could engraft into the liver with advanced fibrosis/cirrhosis and differentiate in hepatocytes, which leads to a repopulation of the parenchyma; also, the cells that were grafted can expand and replace the defective or damaged liver cell population shortly after a cell infusion [11].

The pharmacokinetic effects of $\alpha$ and $\beta$ adrenergic receptor antagonist drugs (doxazosin, tamsulosin, and carvedilol) on the remaining hepatocytes' cell viability, possibly involved in the repopulation of the liver parenchyma during the reversal of fibrosis, are unknown. Therefore, we evaluated in vitro the role of protective of the curcumin on the possible side effects of drugs with antifibrotic activity on the HepG2 cell line. 


\section{Methods}

\section{Cell culture}

HepG2 cells were grown in DMEM (Sigma, D5546) supplemented with $2 \%$ fetal bovine serum (FBS), $2 \%$ Lglutamine (Corning, 25-005-Cl), and $1 \%$ penicillin/streptomycin (Corning, 30-001-Cl) at $37^{\circ} \mathrm{C}$ in a humidified atmosphere containing 5\% CO2 and $95 \% 02$ as proposed by ATCC. After incubation, the cells were rinsed with saline phosphate buffer (PBS, pH 7.4) after adding $1 \mathrm{ml}$ of trypsin EDTA at $0.25 \%$ for 7 min to digest the cells. DMEM was added to finish digestion. The cells were then collected by centrifuging at 2,000 rpm for 5 minutes. All cells were harvested in the logarithmic phase of the experiments.

\section{Treatments with doxazosin, carvedilol, and tamsulosin}

A stock of doxazosin (Sigma, D9815), carvedilol (Sigma, PHR1265), and tamsulosin (Sigma, T1330) was prepared at a concentration of $50 \mathrm{mM}$ using a $0.08 \%$ DMSO solution as a solvent. Based on this solution, the preset treatments of concentrations of $0.1 \mu \mathrm{M}, 0.3 \mu \mathrm{M}, 0.5 \mu \mathrm{M}, 10 \mu \mathrm{M}, 15 \mu \mathrm{M}$, and $25 \mu \mathrm{M}$ were obtained, using the complete DMEM medium as a solvent.

\section{MTT assay}

The cells grown overnight in 96-well plates at a density of $75 \%$ were treated with the concentrations of a/ $\beta$ adrenoreceptor antagonists for 24,48 , and $72 \mathrm{hrs}$. Interactions were performed in the presence or absence of curcumin $1 \mu \mathrm{M}$ (Sigma, C1386). Cell viability was measured using $5 \mathrm{mg} / \mathrm{mL}$ blue thiazolyl tetrazolium bromide (MTT) (Sigma, M2128) dissolved in PBS. Shortly, the cell culture medium with the treatment was changed to medium with diluted MTT $(1: 10, \mathrm{v} / \mathrm{v})$ and incubated for $4 \mathrm{~h}$ at $37^{\circ} \mathrm{C}$. After removing the incubation medium, formazan crystals were dissolved in $100 \mu \mathrm{L}$ of acid isopropanol ( $84 \mu \mathrm{L}$ $\mathrm{HCl}$ at $25 \%$ in $25 \mathrm{ml}$ isopropanol). MTT reduction was quantified by measuring the light absorbance at $595 \mathrm{~nm}$ with a reference filter of $655 \mathrm{~nm}$ using a Microplate reader spectrophotometer, Bio-Rad® .

\section{Measurements of ALT and AST}

The ALT and AST levels were measured by collecting the supernatant of HepG2 cells with treatments in the presence and absence of curcumin and measured the absorbance at $340 \mathrm{~nm}$. The enzyme vitality was calculated according to a standard curve; the concentrations were expressed in international units.

\section{Hematoxylin \& eosin staining}

The cells with the antagonist's adrenergic receptors in the presence and absence of curcumin were plated at $1 \times 105$ cells per well in coverslips at the bottom of 24 -well plates. After the $24 \mathrm{~h}$, the slide inside the plate was withdrawn and washed with PBS 1x, then fixed with $4 \%$ paraformaldehyde for 20 min at room temperature $\left(25^{\circ} \mathrm{C}\right)$, and washed with PBS $1 \mathrm{x}$, stained with $500 \mu \mathrm{L}$ hematoxylin $(1 \mathrm{~min})$, following two washes with distilled water, counterstained with $500 \mu \mathrm{l}$ eosin (20 s), finally the cells were washed twice 
with distilled water and mounted in Mowiol ${ }^{\circledR}$ (Sigma, 81381) and observed under the Axioscop at x20 and $\mathrm{x} 40$.

\section{Scanning electron microscopy}

The HepG2 cells were subjected to scanning electron microscopy analysis to observe the morphological changes upon $\mathrm{a} / \beta$ adrenoblockers in the presence and absence of curcumin during the $24 \mathrm{~h}$ challenge. The cells grown on coverslips in 24-well plates were fixed in $2.5 \%$ glutaraldehyde for 10 minutes at $25^{\circ} \mathrm{C}$. The samples were washed with distilled water and were dehydrated before they were placed on a critical point dryer for 30 mins (IR Chamber Scope). After that, mounting was carried out by sticking the samples onto stubs. Finally, the specimens were gold coated in (Dentuum Vaccum) before viewing under various pressures via scanning electron microscope (JEOL JSM-5900 Low Vacuum SEM).

\section{Acridine orange staining}

To prepare the acridine orange staining solution, the stock was prepared by dissolving $1 \mathrm{~g}$ of $\mathrm{AO}$ in $100 \mathrm{ml}$ of PBS pH 7.4 and was stored at $4^{\circ} \mathrm{C}$ away from light. The HepG2 Cells treated with doxazosin, carvedilol, and tamsulosin were dyed with $1 \mu \mathrm{g} / \mathrm{ml}$. After 15 minutes at $37^{\circ} \mathrm{C}$, the stained cells were washed with PBS. The presence of stained acidic vesicular organelles was assessed using a fluorescence invert microscope Carl Zeiss 398 Axiovert 40CFL Microscope (Carl Zeiss AG, Germany) at the magnification x 20 in maximum emission of $490 \mathrm{~nm}$ as red color and $515 \mathrm{~nm}$ as green color.

\section{Statistical Analysis}

Statistical analysis was achieved using Microsoft Excel and GraphPad Prism 6 software. The results were presented as the mean \pm SD. D'agostino \& Pearson's normality test and the analysis of variance (ANOVA) and Dunnett's post hoc were used for multiple comparisons. $P$ values less than 0.05 were significant and indicated by asterisks as follows: ${ }^{*} P<0.05$, ${ }^{\star \star} P<0.01,{ }^{\star \star *} P<0.001,{ }^{\star \star \star *} \mathrm{P}<0.0001$.

\section{Results}

\section{Cytotoxicity Assessment by MTT assay}

The MTT assay reported that $0.5 \mu \mathrm{M}$ doxazosin induced a timeline and concentration-dependent cytotoxic effect after $24 \mathrm{~h}$, the cell's viability was lowered to $87.81 \pm 3.95 \%$. However, the concentration of $10 \mu \mathrm{M}$ of carvedilol and tamsulosin increased cell proliferation in HepG2 cells (viability $129.0 \pm 4.887 \%$ and $127.5 \pm 5.35 \%$, respectively). Doxazosin induced cytotoxicity at $48 \mathrm{~h}$ with $0.1 \mu \mathrm{M}$ dose (viability 85.81 $\pm 3.53 \%$ ); nevertheless, carvedilol and tamsulosin reduced the viability with $0.1 \mu \mathrm{M}$ to $71.61 \pm 5.24 \%$ and $74.58 \pm 6.03 \%$, with $25 \mu \mathrm{M}$ rise to $88.82 \pm 3.54 \%$ and $101.9 \pm 2.65 \%$. Furthermore, carvedilol and tamsulosin at $72 \mathrm{~h}$ have no impact on HepG2 cells viability; they showed normal viability, without differences versus the control (viability $96.54 \pm 3.62 \%$ and $103.8 \pm 1.778 \%$, respectively). However, the dose of $10 \mu \mathrm{M}$ doxazosin caused cytotoxicity; the viability was $44.28 \pm 3.99 \%$ (Fig. 1). 


\section{Determination of curcumin pretreatment}

The MTT assay results reported that curcumin at low doses $<1 \mu \mathrm{M}$ showed not activity cytotoxic. However, the doses between 10 and $25 \mu \mathrm{M}$ induced cell death (viability $76.33 \pm 1.097$ and $24.01 \pm 0.72 \%$ respectively). These results confirmed that $1 \mu \mathrm{M}$ has no toxic effect in the cells with viability (98.18 \pm $1.39 \%$ ) and was selected as a conventional pretreatment for subsequent experiments (Fig. 2).

\section{Curcumin reduced cytotoxicity induced by $\alpha$ and $\beta$ adrenoblockers}

The results showed that $1 \mu \mathrm{M}$ curcumin for $1 \mathrm{~h}$ before exposure to antagonists reduced the cytotoxicity in HepG2 cells. In this case, the viability of the cells was increased to $98.83 \pm 3.28 \%$ with $25 \mu \mathrm{M}$ of doxazosin, $25 \mu \mathrm{M}$ of carvedilol $115.9 \pm 2.33 \%$, and $25 \mu \mathrm{M}$ of tamsulosin $114.7 \pm 3.77 \%$ (Fig. 3).

\section{Measurements of ALT and AST}

These results showed that HepG2 cells contain a low activity of AST and ALT in the supernatant. The levels of AST and ALT increased in the cells treated with doxazosin (a adrenoblocker) for $72 \mathrm{~h}$ with a dose of $10 \mu \mathrm{M}$ the levels increased to $15.17 \pm 0.40$ and $25 \pm 2.60$, respectively (Fig $4 a$, d). The levels in the cells with carvedilol ( $\beta$ adrenoblocker) only increased with the dose $0.1 \mu \mathrm{M}$ from $12 \pm 0.89$ to $18.33 \pm 1.96$ in AST and $19.50 \pm 1.64$ with ALT (Fig. 4b, e). The treatment with tamsulosin ( $a$ adrenoblocker) report increases in AST from $12 \pm 0.89$ to $14.50 \pm 2.73$ with the dose of $25 \mu \mathrm{M}$ and an increase to $14.67 \pm 1.03$ with dose $0.1 \mu \mathrm{M}$ (Fig. 4c, f). However, compared with the cells exposed to pretreatment with curcumin, doxazosin treatment does not show a difference versus the control, and carvedilol and tamsulosin regulate the enzyme's levels. The antioxidant inhibited the levels of AST and ALT in a dose-dependent manner (Fig 5).

\section{Effects of $\alpha$ and $\beta$ adrenoblockers on the monolayer of HepG2 cells}

The morphological changes of HepG2 cells monolayer after exposure to $a$ and $\beta$ adrenoblockers for $24 \mathrm{~h}$ were described as a decrease in the interaction between the cells compared to the control. The treatment with carvedilol and tamsulosin generated aggregates of eosinophilic cells and cell conglomerates with a dose of $25 \mu \mathrm{M}$. Doxazosin treatment showed balonization dependent on dose. It also showed the general damage at the monolayer detached from neighboring hepatocytes (Fig. 6). However, in the pretreatment with $1 \mu \mathrm{M}$ curcumin, it was observed that the cell culture's viability and morphology were protected during an interaction with doxazosin, tamsulosin, and carvedilol. The cell death decrease, the monolayer's integrity was maintained due to the increased interaction between the cells, fewer cell aggregates were visualized, and the number of balonized cells decreased (Fig. 7).

\section{Ultrastructural effects of $\alpha$ and $\beta$ adrenoblockers on HepG2 cells}

The HepG2 cells showed possible pro-apoptotic changes dependent on the time and the dose of the a and $\beta$ adrenoblockers; at $24 \mathrm{~h}$ interaction, it was found several pro-apoptotic cells (exhibiting cell shrinkage morphology) that appeared to be forming and releasing vesicles, as well cells suffered 
cytoplasmic contraction, nuclear condensation and shedding among neighboring cells. The cells exposed to doses $\geq$ of $10 \mu \mathrm{M}$ of the $\mathrm{a}$ and $\beta$ adrenoblockers presented characteristics such as balonization or cell rounding, condensation of cytoplasmic organelles, and the appearance of irregularities on the cell surface, and the formation of vesiculations followed by cell fragmentation, and the appearance of apoptotic bodies (Fig. 8). However, when the cells were exposed to the pretreatment of curcumin $(1 \mu \mathrm{M})$ before the $\alpha$ and $\beta$ adrenoblockers, the morphology does not show differences between those treated and the control, the morphological characteristics that can be observed are that the villi that represent the intercellular junctions are normal. The cells present a normal nucleus without vesicle formation, indicating the onset of apoptosis or necrosis (Fig. 9).

\section{Detection of apoptosis in cell line HepG2}

The morphological characteristics of the apoptotic cells induced by the $\alpha$ and $\beta$ adrenoblockers were determined by acridine orange staining. The Fig. 10 show that after the incubation of doxazosin and carvedilol for 24 hours, the HepG2 cells developed different morphological changes that include vesiculation or nucleus fragmentation (Red arrow) and formation of apoptotic bodies (white arrow), related to the control cells that show a normal morphology or with respect to the cells treated with curcumin. Curcumin has a protective effect against the possible pro-apoptotic doxazosin, carvedilol, and tamsulosin effects. However, the treatment with curcumin and tamsulosin indicates that the vesicles or apoptotic bodies decrease and increased cells with nuclear condensation (Blue arrow), and the cells treated with the different doses show similarity to the control.

\section{Discussion}

Regarding the background where the $\alpha$ and $\beta$ adrenoceptor blocking drugs were used in liver fibrosis, morphological changes and alteration in liver proliferation markers have been observed. Based on these results, the present study was developed to observe these main findings: cytotoxicity and morphological changes in hepatocytes. These morphological alterations and cytotoxicity have been regulated by pretreatment with curcumin.

In relation to the cytotoxicity of alpha adrenoblockers, investigations have been carried out on the mode of induction of apoptosis and its relationship with the cytotoxicity of different alpha adrenoblockers such as doxazosin, prazosin, 5-methylirapidil, and teratozine in $\mathrm{HL}-1$ cells (derived from cardiomyocytes) as an in vitro model because they maintain the phenotype and intracellular and cell surface elements. It is reported that alpha adrenoblockers doxazosin and prazosin induced apoptosis in a dose-dependent manner, and doxazosin shows significant changes in viability decrease with the $0.1 \mu \mathrm{M} / \mathrm{L}$ dose [10]. These results were confirmed with Hoechst staining, and the studies were made of 24,48 , and $72 \mathrm{~h}$. In our results found that doxazosin has the same behavior at the dose of $0.1 \mu \mathrm{M}$ and time-dependent in HepG2 cells. It is important to remember that in patients, serum doxazosin concentration reaches $0.122 \mu \mathrm{mol} / \mathrm{L}$ with an $8 \mathrm{mg}$ dose and $0.244 \mu \mathrm{mol} / \mathrm{L}$ with a $16 \mathrm{mg}$ dose) [10]. The viability was lowed from the $0.1 \mu \mathrm{M}$ dose at 24 hours. However, carvedilol ( $\beta$ adrenoblocker) with antioxidant activity and selective antagonist 
tamsulosin of a1 A and a1B adrenoceptors showed a significant increase in dose-dependent cell viability at $24 \mathrm{~h}$, and after $72 \mathrm{~h}$, the cell proliferation mechanism was normalized.

Doxazosin is the only adrenoblocker used in the study with high levels of cytotoxicity in the HepG2 cell line. This adverse characteristic of doxazosin has also been reported by different authors, who describe doxazosin as an agent cytotoxic at doses of $25 \mu \mathrm{M}$ in prostate epithelial cell lines [12]. For that reason, we used $25 \mu \mathrm{M}$ as a marker of damage; the viability decreased to $39.07 \pm 8.75 \%$ after $24 \mathrm{~h}$ (Fig. 1). Likewise, under this doxazosin concentration, we observed morphological changes in the hepG 2 cells, such as ballooning, vesicle formation, and positive orange coloration through acridine orange, changes that are related to apoptosis. These morphological changes found in HepG2 cells are similar to those found in prostate cells (LNCaP). The proposed mechanism of damage in an epithelial cell line is through increased activation of caspase 8 by the formation of the death-inducing signaling complex (DISC), caspase 8 can stop the cell cycle in the G2-M phase and thus activate caspase 3 as the tBid responsible for the release of cytochrome $c$ in the BAX/Bak receptor [13]. This results in the release of pro-apoptotic inducing factors related to mitochondrial stress: cytochrome c Smac/DIABLO, AMID, and AIF [14].

Forbes A. et al., 2016 reported that the cytotoxicity of doxazosin and tamsulosin were compared and was demonstrated a dose-dependent increase in the activation of caspase 3 followed by the apoptotic response when the quinazoline structure is present, to confirm this was demonstrated a decrease in HIF-1, a resistance mediator in the LNCaP line after they were exposed to quinazoline [15]. In our study, both aadrenoblockers were also compared at the cytotoxic level, and doxazosin shows the highest decrease in cell viability even in $24 \mathrm{~h}$ treatments. It is proposed because doxazosin has a structure based on quinazoline and tamsulosin in sulfonamide.

It was demonstrated that doxazosin causes an increase in DNA fragmentation, cell cycle arrest in the G2 phase, and apoptosis due to the inactivation of CDK1. Also, it is suggested that doxazosin interrupts the cell cycle by quinazolines thanks to the competitive inhibition of ATP tyrosine kinase and the inhibition of PI3K phosphorylation of EGF and VEGF receptors [16].

Curcumin has therapeutic purposes due to its antioxidant properties [17]. It is an excellent candidate for its low toxicity. However, one of the main characteristics of curcumin is to possess antioxidant and prooxidant properties. We determine the concentration of curcumin that did not induce cell death in the HepG2 cell line for subsequent experiments. In vitro investigations in a model with the cell line, Huh7 exposed to curcumin in very low doses $(\leq 1 \mu \mathrm{M})$, behaves as an antioxidant. However, the doses increased in a range of ( 5 to $10 \mu \mathrm{M}$ ), it behaves as an inducer of autophagy by reducing cytoplasmic proteins' acetylation and blocks the cell cycle, finally with doses greater than $25 \mu \mathrm{M}$, cell death is induced [18]. We used different concentrations with ranges of $0.01,0.03,0.05,0.07,0.1,0.5,1,5,10$, and $25 \mu \mathrm{M}$ during $24 \mathrm{~h}$, and we observed that the doses $\leq 1 \mu \mathrm{M}$ even increased the viability compared to control, cells treated with doses $\geq 5 \mu \mathrm{M}$ significantly decreased viability. Therefore, it was decided to use the concentration of $1 \mu \mathrm{M}$ (Fig. 2). 
Our cell viability results with $1 \mu \mathrm{M}$ curcumin pretreatment showed a recovery of cell viability in MTT up to $100 \%$ compared to control cells (Fig. 3). Possibly because the drugs doxazosin, carvedilol, and tamsulosin induced cell death may be due to oxidative stress, and curcumin with the defense mechanisms like the antioxidant response element (ARE) regulates the expression of genes involved in the elimination of ROS and increased the cell viability; however, these regulatory mechanisms are not entirely understood [19].

The main indicator enzymes of oxidative stress and liver damages are AST and ALT [20]. Previous studies have demonstrated in a HepG2 cell model the effect of glycyrrhizate (an antioxidant) on antioxidant defense systems by analyzing AST and ALT levels with and without $\mathrm{H}_{2} \mathrm{O}_{2}$, showing that $\mathrm{H}_{2} \mathrm{O}_{2}$ induces an increase in the levels of the enzymes. Glycyrrhizinate pretreatment effectively protected HepG2 cells from induced damage and decreased ALT and AST [21]. We reported that AST and ALT enzymes of HepG2 cells exposed to different concentrations of $\alpha$ and $\beta$ adrenoblockers increased with the concentrations of 0.1 and $10 \mu \mathrm{M}$ of doxazosin, 0.1 and $25 \mu \mathrm{M}$ carvedilol, and $0.1 \mu \mathrm{M}$ tamsulosin (Fig. 4). However, curcumin pretreatment decreased AST and ALT levels, counteracting the drugs' possible oxidative effect (Fig. 5).

The effect of cycloheximide in liver cells at the histological level with hematoxylin and eosin staining and the ultrastructural level with scanning electron microscopy described apoptosis stages in rat hepatocytes in four sequential phases: 1) cell contraction, 2) cell fragmentation, 3) release of blood cells in the sinusoids, 4) phagocytosis and digestion of blood cells by hepatocytes and Kupffer cells, we report in our study that the changes morphological of the HepG2 cells, occurred at $24 \mathrm{~h}$ after interaction with the alpha and beta adrenoblockers following the patterns indicated above; though after cycloheximide-induced oxidative stress, is compared to histological and ultrastructural findings thioacetamide-induced apoptosis [22]. In the evaluation of the cell monolayer by hematoxylin and eosin, we observed that $a$ and $\beta$ adrenoblockers alter the formation of the monolayer and decrease cell interaction, and there are eosinophilic aggregates or apoptotic process. However, with curcumin, the monolayer is restored and cellular interaction (Figs. 6 and 7). Another of the hepatocytes' characteristics was ultrastructures which suggest a progressive fragmentation of the cell body, and each fragment gives rise to an apoptotic body. We report the ultrastructures' with SEM that indicate that doxazosin, carvedilol, and tamsulosin induce possible pro-apoptotic processes that are time and dose-dependent. However, doxazosin shows more morphological changes such as balonization and separation of cells that result in the formation of vesicles or possible apoptotic bodies; carvedilol and tamsulosin show minor changes in cells as irregular surfaces with radiated projections. Curcumin treatment reduces the morphological variations, and the cell morphology shows normal villi and intercellular junctions without vesicles, indicating that it inhibits the apoptotic process.

In vitro studies, in HepG2 cells, cell death mechanisms were studied from the red signal of the acridine orange stain of different compounds that generate oxidative stress such as $\mathrm{H}_{2} \mathrm{O}_{2}$-relating a greater signal with the fragmentation of cellular structures and the beginning of the apoptotic process. The positive damage control showed high red coloration within the nucleus [23]. We observed that the three 
drugs induce the dose-dependent apoptotic response due to the increase in color in the cells compared to our damage control $\left(\mathrm{H}_{2} \mathrm{O}_{2}\right)$; however, this red signal decreased when the cells were analyzed with curcumin, proving that it can have an anti-apoptotic effect.

\section{Conclusion}

The present study demonstrates that curcumin protected the HepG2 cells against cytotoxicity and morphological changes induced by the $\alpha$ and $\beta$ adrenoblockers attenuating secondary effects and therefore could serve as a treatment for the regeneration process of the liver parenchyma in the regression of fibrosis with a-adrenoblockers (doxazosin and tamsulosin) and $\beta$-adrenoblocker carvedilol.

\section{Abbreviations}

a: Alpha; $\beta$ : Beta; $\mu$ l: Microliter; ALT: Alanine aminotransferase; AO: Acridine Orange; AST: Aspartate aminotransferase; $\mathrm{CCl}_{4}$ : Carbon tetrachloride; $\mathrm{CO}_{2}$ : Carbon dioxide; DMSO: Dimethyl sulfoxide; DMEM:

Medio Dulbecco's Modified Eagle's Medium - low glucose; $\mathrm{H}_{2} \mathrm{O}_{2}$ : Hydrogen peroxide; MTT: (3-(4,5dimethylthiazolyl-2)-2,5-diphenyltetrazolium bromide); Nrf2: Nuclear factor erythroid-derived 2-like 2; ROS: Reactive oxygen species; SEM: Scanning electron microscope.

\section{Declarations}

\section{Ethics approval and consent to participate}

Not applicable

\section{Consent for publication}

Not applicable

\section{Availability of data and materials}

The datasets used and/or analyzed during the current study are available from the corresponding author on reasonable request.

\section{Competing interests}

The authors declare that they have no competing interests.

\section{Funding}

The present study was supported by CONACYT (grant 241312 and A1-S-21375) and the Autonomous University of Aguascalientes (grant PIBB18-8). MYMP gratefully acknowledges the financial fellowship granted by CONACYT (no. 907029) as part of the master's program in Toxicology Sciences of the Autonomous University of Aguascalientes. 


\section{Authors' contributions}

MYMP and MNMR developed cytotoxicity techniques, $\mathrm{H} \& \mathrm{E}$ and $\mathrm{AO}$ staining, phase contrast microscopy, and electron microscopy during the treatments with a-adrenoblockers (doxazosin and tamsulosin) and $\beta$ adrenoblocker carvedilol and the analysis and interpretation of the data of cytotoxicity, biochemical measurements, staining, and scanning electron microscopy. ESA and LRAM developed the biochemical measurements AST and ALT. SLMH, JVJ and MHMO contributed to study conception and design, and the writing and revision of the manuscript. All authors read and approved the final manuscript.

\section{Acknowledgements}

We acknowledge to Immunoparasitology laboratory by the donation of the HepG2 cell line, Autonomous University of Aguascalientes; and LAQB Cintya Esquivel-Dueñas and LAQB Mariana Perez-Villalobos, Department of Chemistry, Autonomous University of Aguascalientes, for their excellent technical assistance.

\section{References}

1. Serna-Salas SA, Navarro-González YD, Martínez-Hernández SL, Barba-Gallardo LF, Sánchez-Alemán E, Aldaba-Muruato LR, Macías-Peréz JR, Ventura-Juárez J, Muñoz-Ortega MH. Doxazosin and Carvedilol Treatment Improves Hepatic Regeneration in a Hamster Model of Cirrhosis. Biomed Res Int. 2018;2018:1-11.

2. El-Demerdash E, Abdel-Sattar SA, El-Bakly WM, Mohamed EA. Antifibrotic Effects of Carvedilol and Impact of Liver Fibrosis on Carvedilol Pharmacokinetics in a Rat model. Eur J Drug Metab Pharmacokinet. 2017;42(5):767-79.

3. Ling L, Li G, Wang G, Meng D, Li Z, Zhang C. Carvedilol improves liver cirrhosis in rats by inhibiting hepatic stellate cell activation, proliferation, invasion and collagen synthesis. Mol Med Rep. 2019;20(2):1605-12.

4. Goel A, Kunnumakkara AB, Aggarwal BB. Curcumin as "Curecumin": from kitchen to clinic. Biochem Pharmacol. 2008;75(4):787-809.

5. Priyadarsini KI. The chemistry of curcumin: from extraction to therapeutic agent. Molecules. 2014;19(12):20091-20112.

6. Chattopadhyay D, Somaiah A, Raghunathan D, Thirumurugan K. Dichotomous Effect of Caffeine, Curcumin, and Naringenin on Genomic DNA of Normal and Diabetic Subjects. Scientifica. 2014;2014:1-7.

7. Balogun E, Hoque M, Gong P, Killeen E, Green CJ, Foresti R, Alam J, Motterlini R. Curcumin activates the haem oxygenase-1 gene via regulation of Nrf2 and the antioxidant-responsive element. Biochem J. 2003;371(Pt3):887-95. 
8. Macías-Pérez JR, Vázquez-López BJ, Muñoz-Ortega MH, Aldaba-Muruato LR, Martínez-Hernández SL, Sánchez-Alemán E, Ventura-Juarez J. Curcumin and a/ $\beta$-Adrenergic Antagonists Cotreatment Reverse Liver Cirrhosis in Hamsters: Participation of Nrf-2 and NF- KB. J Immunol Res. 2019;2019:112.

9. Forbes A, Anoopkumar-Dukie S, Chess-Williams R, McDermott C. Relative cytotoxic potencies and cell death mechanisms of a1-adrenoceptor antagonists in prostate cancer cell lines. Prostate. 2016;76(8):757-66.

10. González-Juanatey JR, Iglesias MJ, Alcaide C, Piñeiro R, Lago F. Doxazosin Induces Apoptosis in Cardiomyocytes Cultured In Vitro by a Mechanism That Is Independent of a;1-Adrenergic Blockade. Circulation. 2003;107(1):127-31.

11. Yovchev MI, Xue Y, Shafritz DA, Locker J, Oertel M. Repopulation of the fibrotic/cirrhotic rat liver by transplanted hepatic stem/progenitor cells and mature hepatocytes. Hepatology. 2014;59(1):28495.

12. Garrison JB, Kyprianou N. Doxazosin induces apoptosis of benign and malignant prostate cells via a death receptor-mediated pathway. Cancer Res. 2006;66(1):464-72.

13. Desiniotis A, Kyprianou N. Advances in the design and synthesis of prazosin derivatives over the last ten years. Expert Opin Ther Targets. 2011;15(12):1405-18.

14. Harris AM, Warner BW, Wilson JM, Becker A, Rowland RG, Conner W, Lane M, Kimbler K, Burbin EB, Baronand AT, Kyprianou N. Effect of a1-adrenoceptor antagonist exposure on prostate cancer incidence: an observational cohort study. J Urol. 2007;178(5):2176-80.

15. Keledjian K, Kyprianou N. Anoikis induction by quinazoline based alpha 1-adrenoceptor antagonists in prostate cancer cells: antagonistic effect of bcl-2. J Urol. 2003;169(3):1150-6.

16. Anglin IE, Glassman DT, Kyprianou N. Induction of prostate apoptosis by a1-adrenoceptor antagonists: mechanistic significance of the quinazoline component. Prostate Cancer Prostatic Dis. 2002;5(2):88-95.

17. Hatcher H, Planalp R, Cho J, Torti FM, Torti S V. Curcumin: From ancient medicine to current clinical trials. Cell Mol Life Sci. 2008;65(11):1631-52.

18. Rainey N, Motte L, Aggarwal BB, Petit PX. Curcumin hormesis mediates a cross-talk between autophagy and cell death. Cell Death Dis. 2015;6(12):e2003.

19. Kensler TW, Wakabayashi N, Biswal S. Cell Survival Responses to Environmental Stresses Via the Keap1-Nrf2-ARE Pathway. Annu Rev Pharmacol Toxicol. 2007;47(1):89-116.

20. Torun AN, Kulaksizoglu S, Kulaksizoglu M, Pamuk BO, Isbilen E, Tutuncu NB. Serum total antioxidant status and lipid peroxidation marker malondialdehyde levels in overt and subclinical hypothyroidism. Clin Endocrinol (Oxf). 2009;70(3):469-74.

21. Su M, Yu T, Zhang H, Wu Y, Wang X, Li G. The Antiapoptosis Effect of Glycyrrhizate on HepG2 Cells Induced by Hydrogen Peroxide. Oxid Med Cell Longev. 2016;2016:1-9.

22. Faa G, Ledda-Columbano GM, Amhu R, Congiu T, Coni P, Riva A, Columbano A. An electron microscopic study of apoptosis induced by cycloheximide in rat liver. Liver. 1994;14(5):270-8. 
23. Plemel JR, Caprariello AV, Keough MB, Henry TJ, Tsutsui S, Chu TH, Schenk GJ, Klaver R, Yong VW, Stys PK. Unique spectral signatures of the nucleic acid dye acridine orange can distinguish cell death by apoptosis and necroptosis. J Cell Biol. 2017;216(4):1163-81.

\section{Figures}
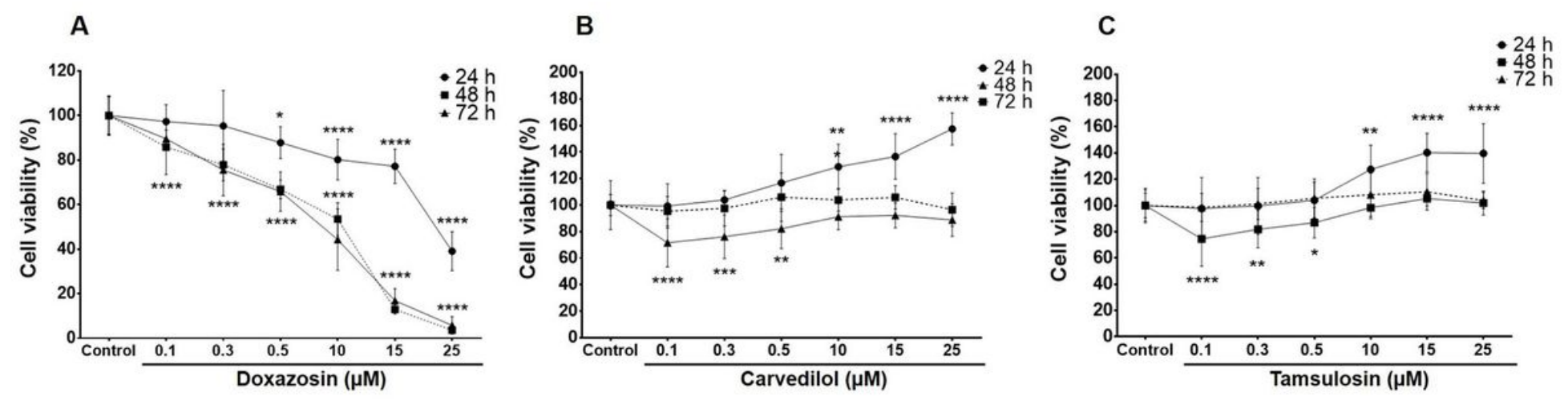

Figure 1

Doxazosin reduces cell viability timeline and dose-dependent in the HepG2 cell line. Carvedilol induces proliferation of HepG2 cells. Tamsulosin maintains viability and possibly induces proliferation in the cell line. The viability was analyzed by the MTT assay and is presented relative to the activity at the start of the experiment in each case. The results are from three independent experiments. Data are mean $\pm S D,{ }^{*} p$ $<0.05,{ }^{\star \star} p<0.0025,{ }^{\star \star \star} \mathrm{p}<0.001,{ }^{\star \star \star \star} \mathrm{p}<0.0001$ versus Control. 


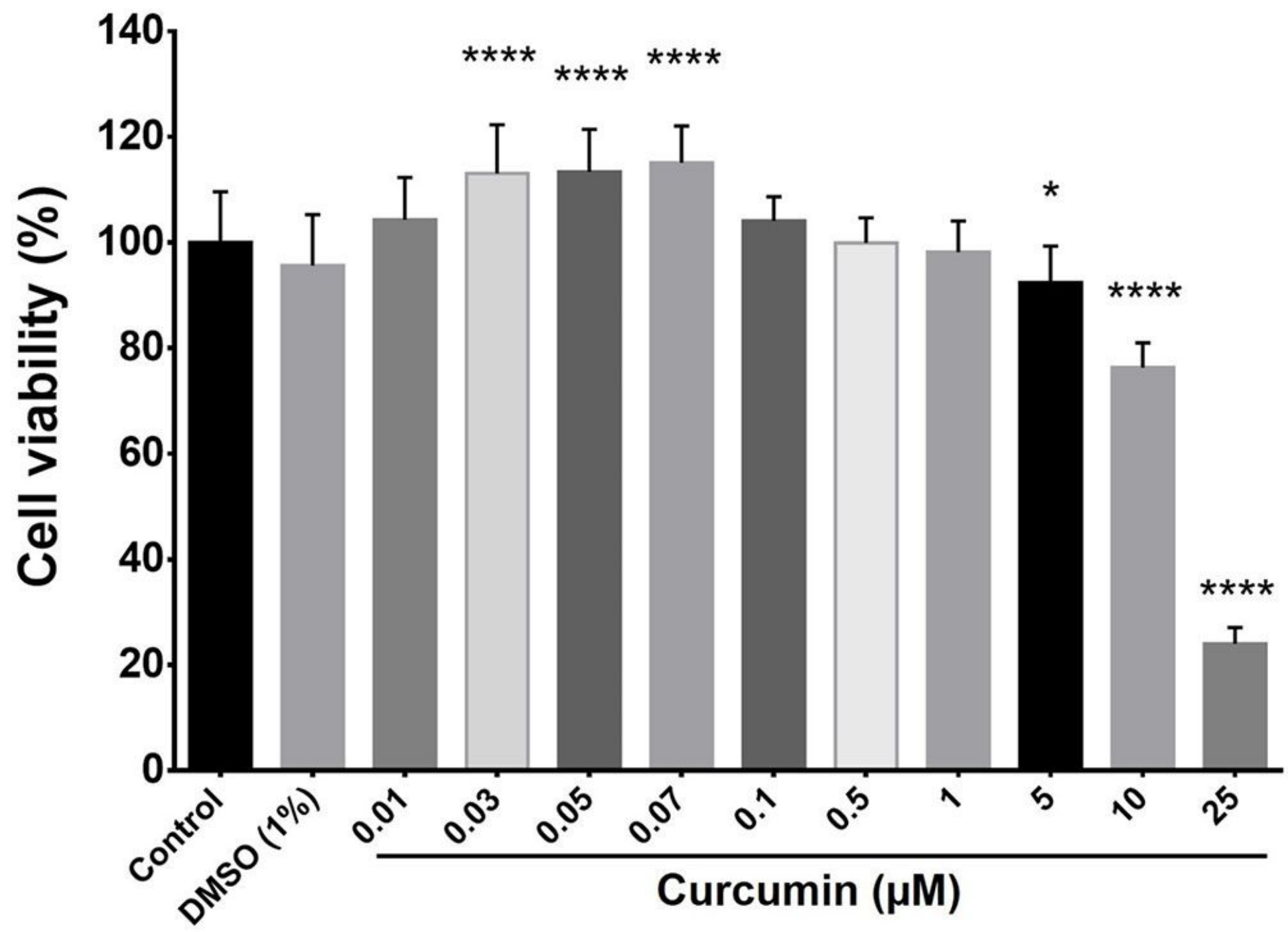

Figure 2

Curcumin hormesis in HepG2 cells. The viability was analyzed by the MTT assay for $24 \mathrm{~h}$ and is presented relative to the activity at the start of the experiment in each case. The results are from four independent experiments. Data are mean $\pm S D$, ${ }^{\star} p<0.05$, ${ }^{\star \star \star *} p<<0.0001$ versus Control.
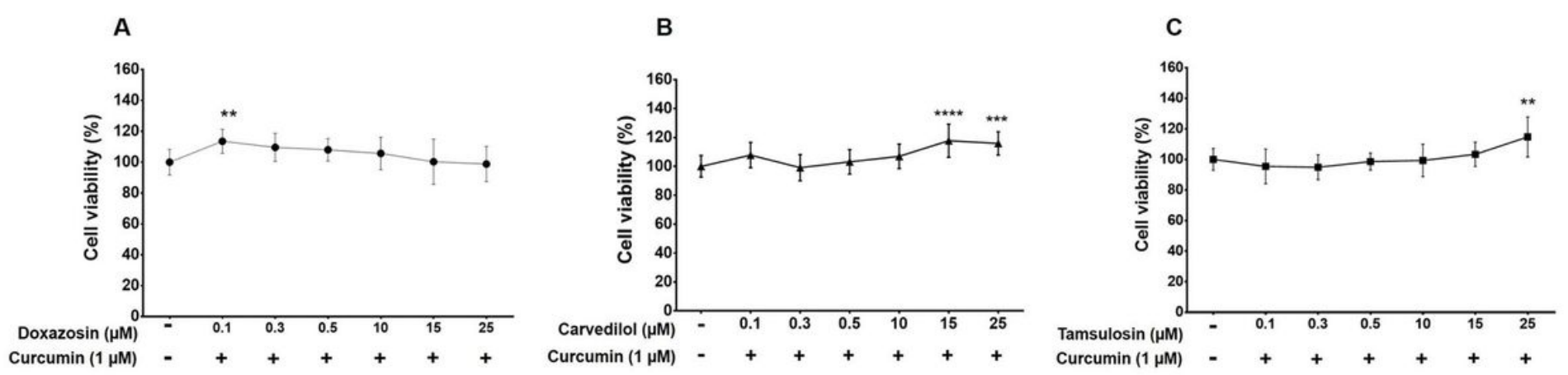

Figure 3 
Curcumin pretreatment inhibits cytotoxicity in HepG2 cells treated with doxazosin, carvedilol, and tamsulosin. Curcumin protects HepG2 cells against the induced cytotoxicity. Cell viability was analyzed by MTT assay. The results are from three independent experiments. Data are mean $\pm S D, * \star p<0.0025$, $* \star * p<0.001, * * * * p<0.0001$ versus Control.

A

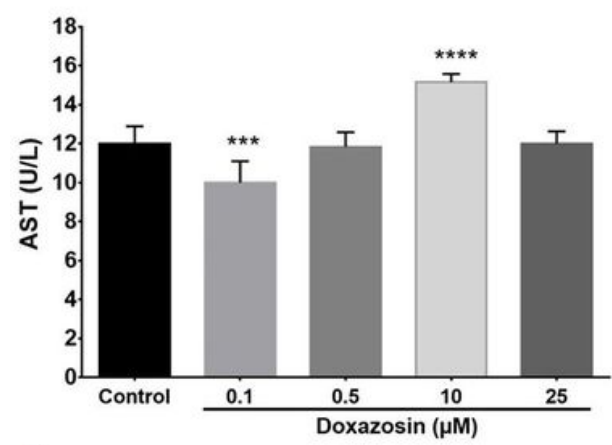

D

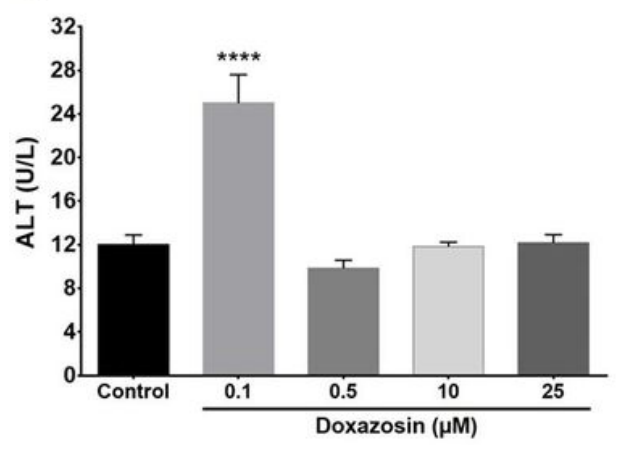

B
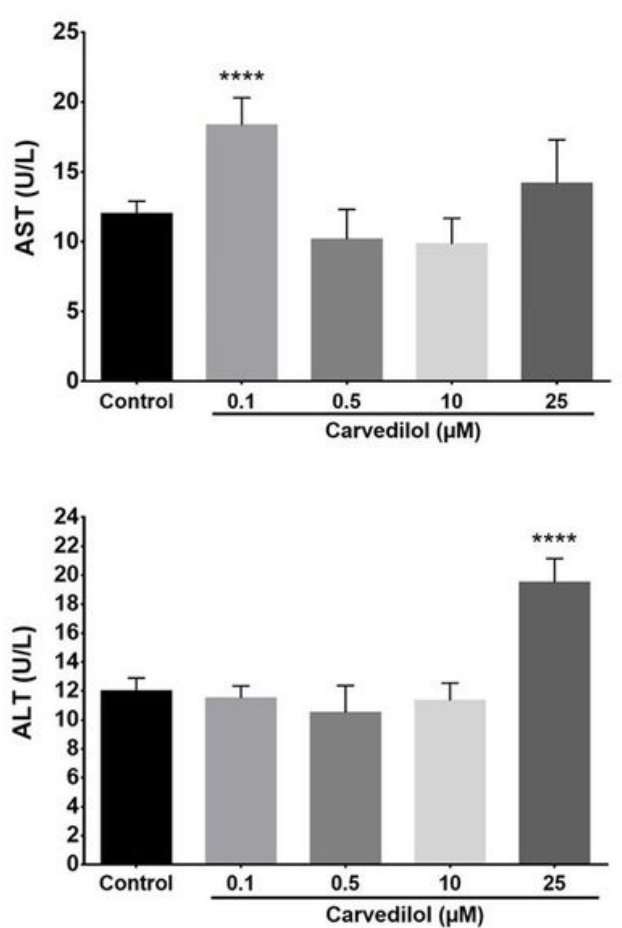

C

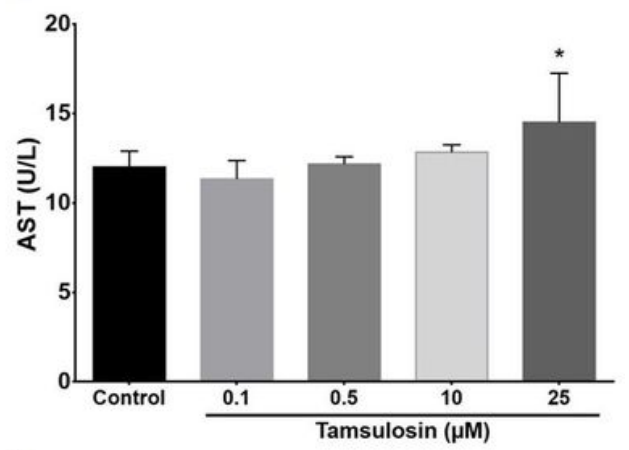

$\mathrm{F}$

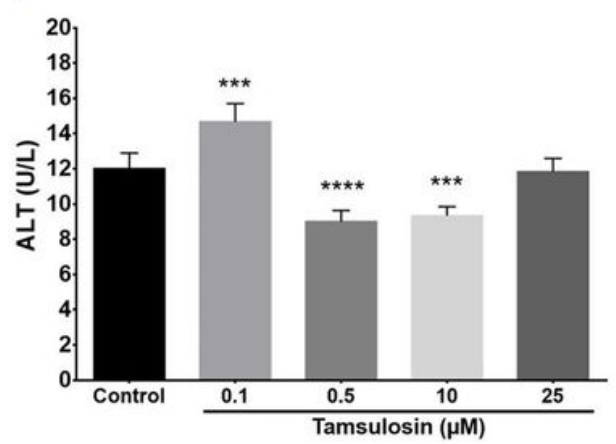

Figure 4

The cell permeability changes during the treatment with $\alpha$ and $\beta$ adrenoreceptors by AST and ALT levels. The drugs doxazosin, carvedilol, and tamsulosin increase transaminase levels. The ALT and AST in the culture medium were determined after $72 \mathrm{~h}$. Data are mean $\pm S D, n=6,{ }^{\star} p<0.05,{ }^{\star * \star} p<0.001$, ${ }^{\star \star \star \star} p<$ 0.0001 versus Control. 

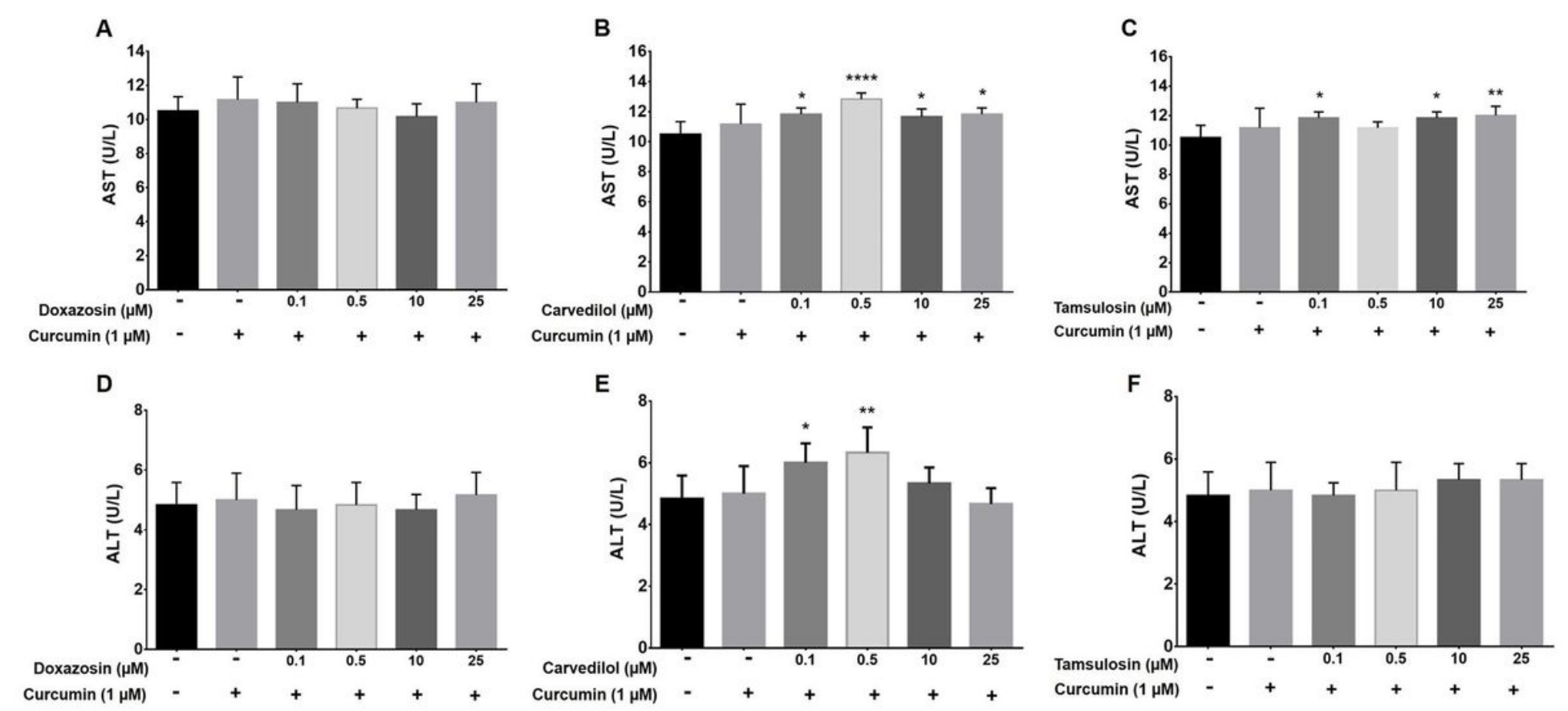

\section{Figure 5}

Curcumin controls the release of cell-damaging enzymes AST and ALT by a possible change in permeability induced by doxazosin, carvedilol, and tamsulosin. The content of ALT and AST in cells with curcumin treatment and $\alpha / \beta$ adrenoblockers was determined after $24 \mathrm{~h}$. Data are mean $\pm S D, n=6$, $p^{2}<$ $0.05,{ }^{*} \mathrm{p}<0.0025, * \star * \star \mathrm{p}<0.0001$ versus Control.

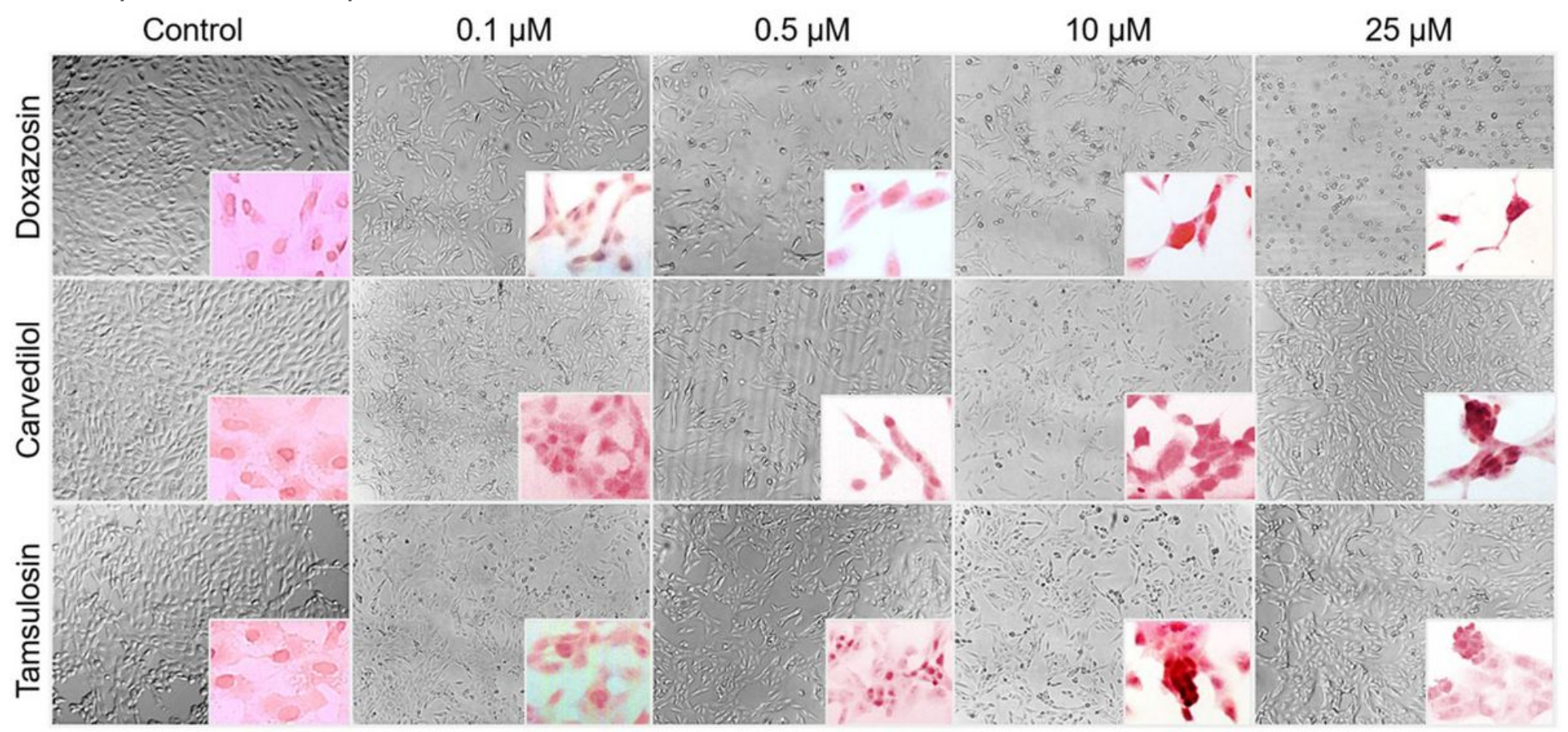

\section{Figure 6}

Morphological effects on the monolayer of HepG2 cells exposed to $a$ and $\beta$ adrenoblockers. The arrows indicate the cells' main morphological changes as alteration of the monolayer, decreased cell interaction, 
aggregates of eosinophilic cells, and balonization. Treatments for $24 \mathrm{~h}$ were visualized by hematoxylin and eosin staining taken at $\times 40$.

\section{Curcumin $1 \mu \mathrm{M}$}

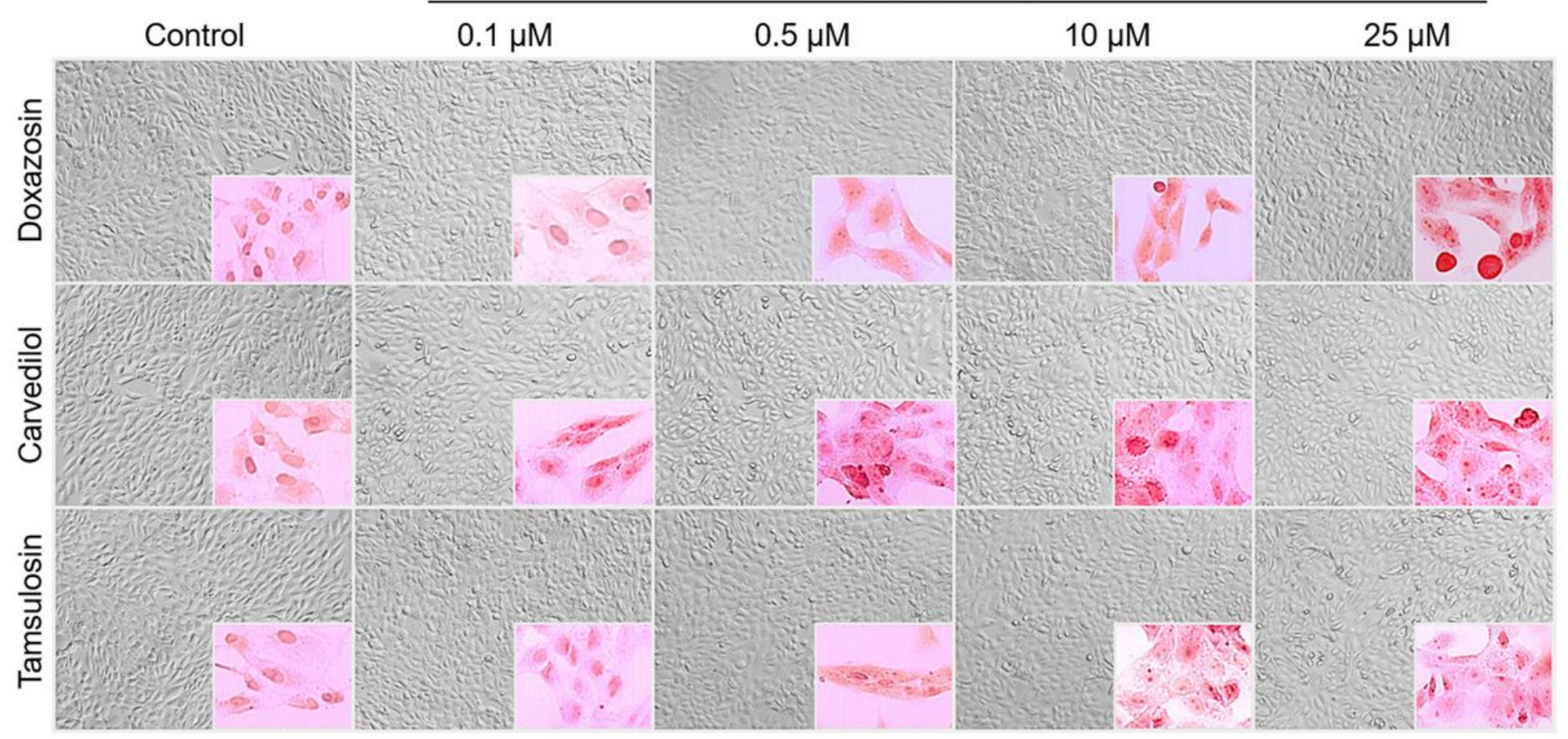

\section{Figure 7}

Curcumin protects the integrity of the monolayer during an interaction with proven antifibrotic drugs. Curcumin decreases the amount of cell death, maintains the integrity of the monolayer, increases the interaction between cells, reduces cell aggregates, and decreases balonization (arrow). Treatments for 24 $\mathrm{h}$ were visualized by hematoxylin and eosin staining taken at $40 \mathrm{x}$ zoom.

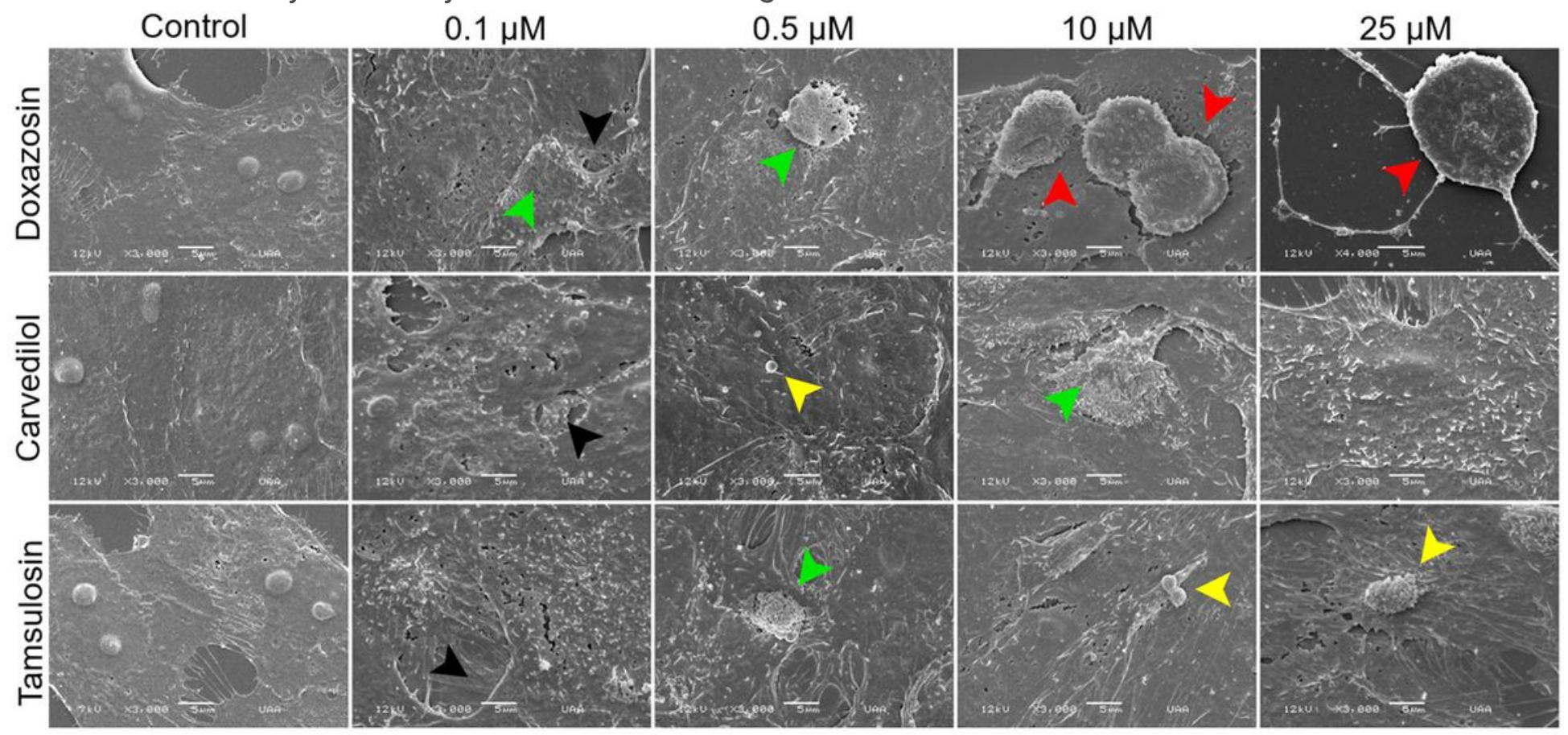




\section{Figure 8}

Ultrastructural effects of doxazosin, carvedilol, and tamsulosin on HepG2 cells. Black arrow: irregular cell surface with folds of the cell membrane. Green arrow: cell contraction with the formation of vesicles followed by fragmentation. Red arrow: balonization resulting in separation of neighboring cells. Yellow arrow: possible apoptotic body. The treatments during $24 \mathrm{~h}$ were visualized under an SEM (scale bar of 5 $\mu \mathrm{m})$.

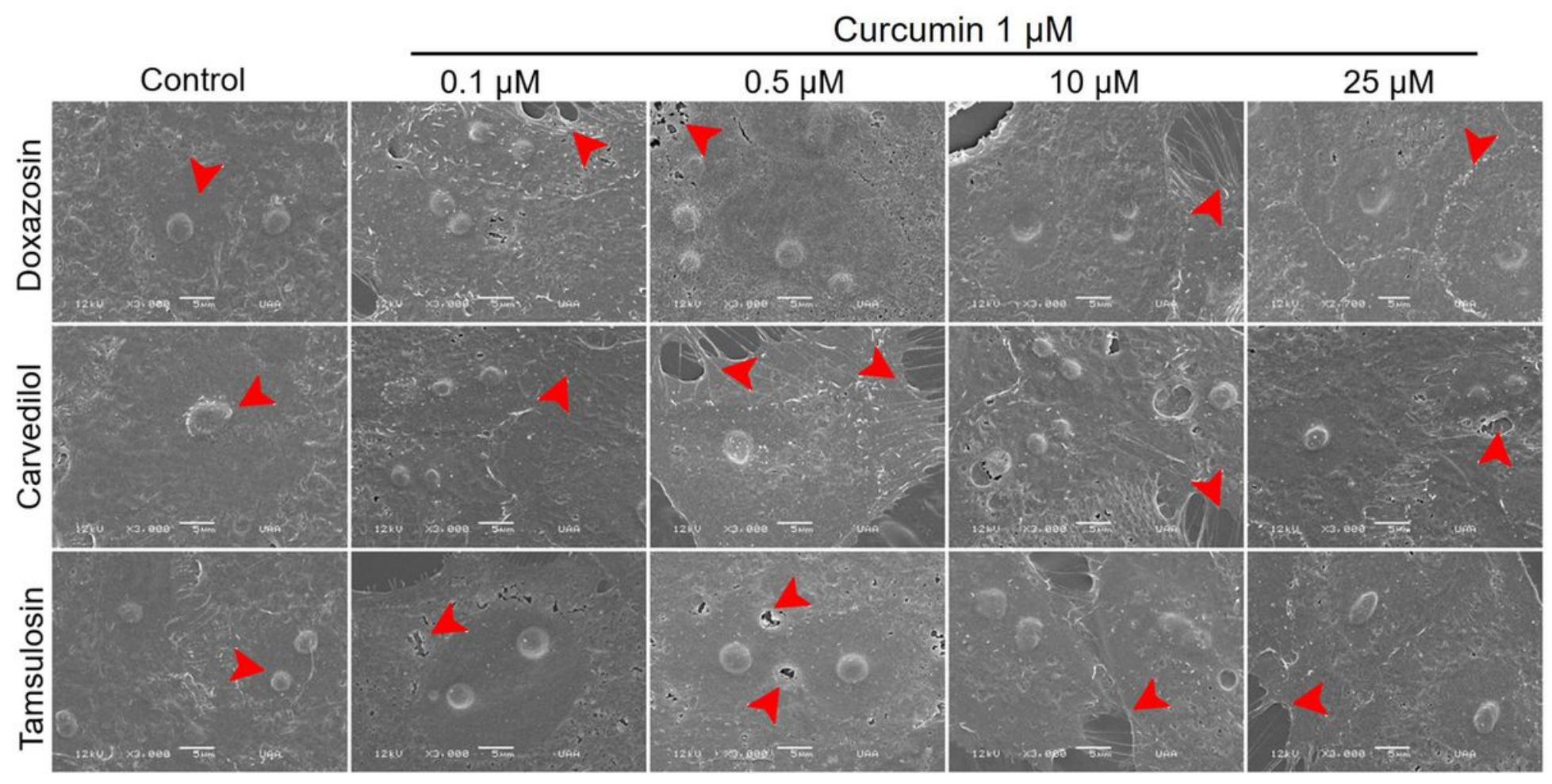

\section{Figure 9}

Curcumin reduces the morphological variations related to cell damage caused by $a$ and $\beta$ adrenoceptor blocking drugs. Cell morphology shows normal villi and intercellular junctions (red arrow) without vesicle formation in HepG2 cells. Treatments for $24 \mathrm{~h}$ were visualized under SEM ( $5 \mu \mathrm{m}$ scale bar). 


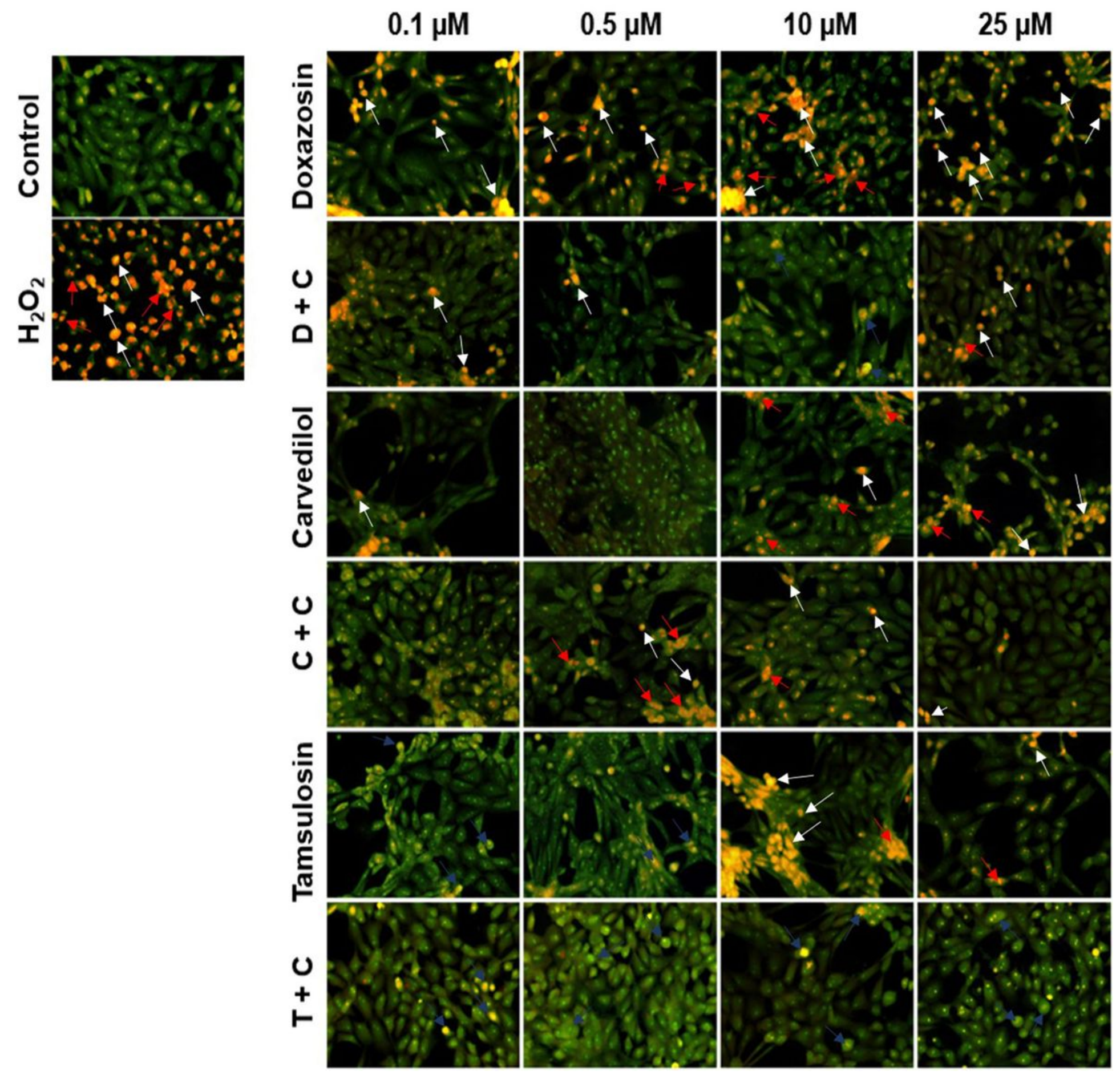

Figure 10

Curcumin protects HepG2 cells from the pro-apoptotic effect of doxazosin and carvedilol. Tamsulosin is less susceptible to cell death. The untreated live cells showed normal green nuclei (Control). White arrow: apoptotic bodies. Blue arrow: chromatin condensation. Red arrow: nucleus fragmentation. Treatments for $24 \mathrm{~h}$ were visualized by acridine orange staining taken at $20 \times$ zoom. Doxazosin + Curcumin $(D+C)$, Carvedilol + Curcumin $(C+C)$, Tamsulosin + Curcumin $(T+C)$. 